\title{
Evaluation of incidence and pattern of third molar impactions in Jammu region: A cross sectional study
}

\author{
Kamal Kishore', Parveen Akhter Lone ${ }^{2 *}$, Zubair Ahmed Janbaaz ${ }^{3}$, Mehnaz $^{4}$, Bashir Ahmed Lone ${ }^{5}$ \\ ${ }^{\mathbf{1}}$ Associate Professor, ${ }^{2}$ Professor and Head, ${ }^{3,4}$ House Surgeon, ${ }^{5}$ Curator, ${ }^{1}$ Dept. of E.N.T, ${ }^{2-4}$ Dept. of Oral \& Maxillofacial Surgery (OMFS), \\ ${ }^{5}$ Dept. of Geology, ${ }^{1}$ Government Medical College SMGS Hospital, (Affiliate to University of Jammu), ${ }^{2-4}$ Indira Gandhi Government \\ Dental College (IGGDC) (Affiliate to University of Jammu), ${ }^{5}$ University of Jammu, Jammu \& Kashmir, India
}

\section{*Corresponding Author: Parveen Akhter Lone}

Email: parveen.lone@yahoo.com

\begin{abstract}
Aims and Objectives: The aim and objective is to evaluate the frequency of third molar impactions, their angulations, and percentage of agenesis in mandible within the demographic confines of Jammu region of Jammu. The pattern of third molar impactions shows variation with respect to different population. Besides, impacted third molars engender potential pathologic complications.

Materials and Methods: The sample consists of 310 orthopantomogram from patients who reported to the department of oral and maxillofacial surgery IGGDC Jammu throughout a period of one year. Data regarding age, gender, prevalence and pattern of third molars were collected and analysed.

Results: Among 310 patients, 183 were male and 127 were female. The percentage of impactions was higher in case of females than males. Moreover, females had a marginally higher rate of agenesis than males. Mandibular impactions had a higher percentage than maxillary impactions. Mesioangular was the most prevalent angulation. Percentage of vertical impactions in maxilla exceeded that in mandible.
\end{abstract}

Keywords: Third molar, Agenesis, Impaction, Orthopantomogram, Mesioangular.

\section{Introduction}

The mandibular third molars are the most frequently impacted teeth that can be found in human. ${ }^{1}$ Causes of impactions have been broadly classified as local and systematic. Impacted teeth are often associated with pericoronitis, periodontitis, cystic lesions, neoplasm, root resorption and can cause detrimental effects on adjacent tooth. $^{2}$

Prevalence and pattern of third molar impactions presents a varied picture across the globe. The prevalence of third molar impaction ranges from $16.7 \%$ to $68.6 \% .^{3-10}$ Variance among males and females has also been observed. Some studies have reported no sexual predilection in third molar impaction. ${ }^{3,4,6,8}$ Whereas some studies have reported a higher frequency in females than males. ${ }^{10,11}$ Furthermore, the agenesis of third molars can be either genetic or due to lifestyle and dietary habits. ${ }^{12}$

Classification is based on the level of impaction, ${ }^{13}$ the angulations of the third molars and the relationship to the anterior border of the ramus of the mandible. Depth or level of maxillary and mandibular third molars can be classified using the Pell and Gregory classification system, where the impacted teeth are assessed according to their relationship to the occlusal surface (OS) of the adjacent second molar. ${ }^{14}$

Hence the current study aims to evaluate the incidence of third molar impactions and agenesis in maxilla and mandible and their incidence in males and females.

\section{Materials and Methods}

The study was performed at the department of Oral and maxillofacial surgery for a period of one year. OPG's from 310 patients (183 males +127 females) were collected after obtaining an informed consent.
The OPGs of patients in the age group of 18-40 were included. The patients below 18 years of age, those having any history of maxillo-facial trauma, craniofacial anomalies, third molars with incomplete root formation and those with missing second molars were excluded from the study.

The OPG's were evaluated using a radiographic viewer and were interpreted for impactions of maxillary and mandibular third molars, agenesis of third molars and angulation of the impacted third molar teeth. The demographic variables recorded were age and gender. A third molar was considered as impacted when it was devoid of functional occlusion while the root formation is completed. An orthodontic protractor was used to measure the angle between the longitudinal axis of second and third molars. Accordingly the angulations were determined as: mesioangular \& distoangular (10-70 degrees); vertical (<10 degree); horizontal (>70 degree) $\{$ Shiller, 1979\}.

\section{Results}

A total of 310 patients were included in the study of which 183 were male and 127 female patients (Fig. 1). The mean age of patients was 23 years. A total of 595 impacted teeth were analysed of which 337 were in males and 258 in females. (Fig. 2) Total impacted mandibular and maxillary third molars were 442 and 153 respectively. (Fig. 3) The percentage of impactions in males was $51.7 \%$ and in females was $56.33 \%$, agenesis was found to be $8 \%$ (59 potential teeth) in males and $11 \%$ (56 potential teeth) in females. Number of impacted third molars in maxilla were $153(25.7 \%)$ and $442(74.3 \%)$ in the mandible. (Table 1) The most prevalent angulation was mesioangular. (Table 2) 


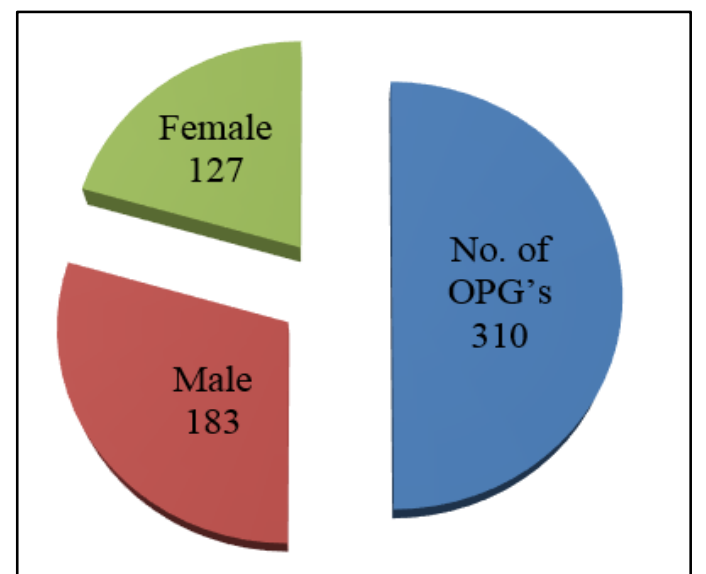

Fig. 1

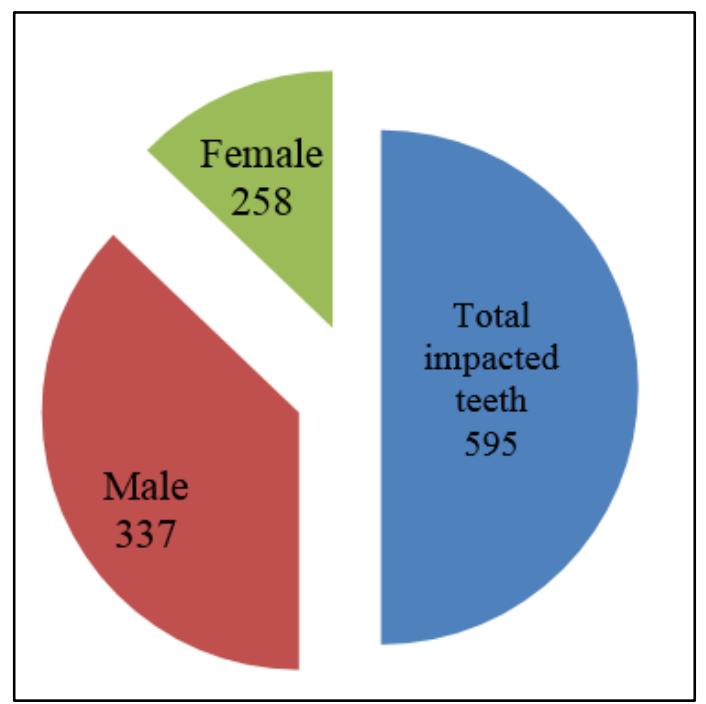

Fig. 2

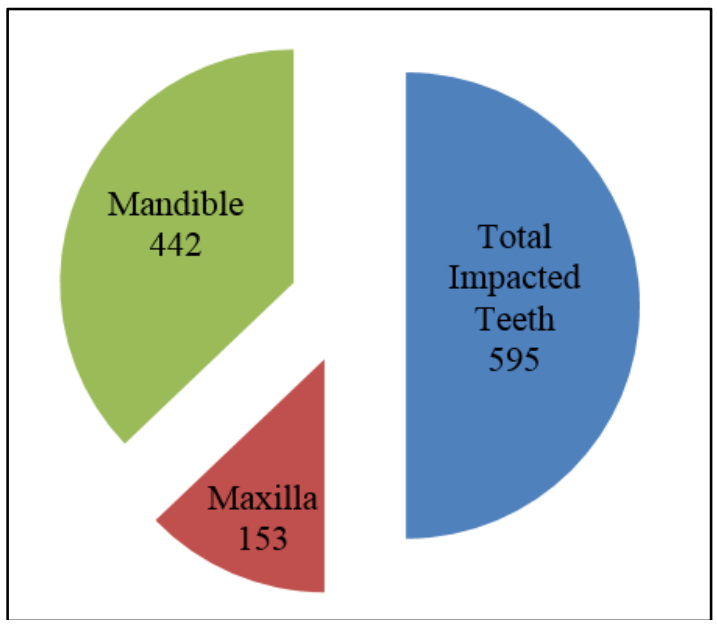

Fig. 3

\section{Discussion}

Tooth impaction is a pathologic condition where a tooth does not erupt into its normal functional position. The mandibular third Molars are most frequently impacted teeth that is common problem affecting a large population in the world..$^{15}$ The incidence of third molar impaction in this study impacted teeth was seen in $52.1 \%, 310 / 595$ literature also reported the incidence of impactions higher by Morris \& Jerman ${ }^{16}$ who reported $65.6 \%$ in study of 5000 subjects in united states of America \& 68.6\% in sample of 1000 subjects in Singapore. ${ }^{16}$ However a lower prevalence was reported in some studies reported by Momtelius 32\% Hattab et al $33 \%$ \& Hassan $40.8 \% .4,17,18$

Previous studies have reported higher incidence of impactions $19.3 \%$ in patients above 40 years of age in contrast to the present study the mean age of patients having high rate of impactions was 23 years in correlation with studies reported by. Ma'aita J, \&. Breik O, Grubor D., ${ }^{2,14}$ This may be due to awareness amongst young \& present generation about oral health \& seeking treatment of any oral disease at early detection.

In the present study Impactions were found higher in females as compared to males.

The percentage of impactions in males was $51.7 \%$ and in females was $56.33 \%$, agenesis was found to be $8 \%$ (59 potential teeth) in males and $11 \%$ (56 potential teeth) in females in agreement with studies reported gender predilection for females by Hashemipour et al..$^{2,10,11,19}$ It can be due the fact that physical growth in females usually stops before males leading to small size of the jaws \& also the initiation of third molar eruption normally occur after the growth of jaws is stopped, in men jaw growth continues during the third molar eruption providing more space for the tooth. ${ }^{10,15,20}$

The most prevalent angulation was mesioangular in the present study followed by vertical \& horizontal impaction in accordance with findings of Kramer \& Williams, Quaker et al, Morris \& Jerman, Hassan et al \& Hashemipour et al. ${ }^{9,16,18,19}$ the studies reported by these authors show that mesioangular was the most common type of impaction in mandibular molars of African Americans, sinaporeans, Americans, Arabian, Arabians \& Iranians respectively.

The aetiology of smaller jaw size is believed to be changes in lifestyle so the space available for third molar is reduced ${ }^{20}$ in addition delayed third molar mineralization \& early physical maturation is possible reason of high impaction rate further racial differences can affect the maturation 7 eruption timings \& also the size of jaws. ${ }^{21}$

The limitation of this study was that it was cross sectional study done on OPG radiographs \& covered only a limited region of Jammu population. So in order to evaluate aetiology of third molar impaction \& also to perform randomized study in population from different regions further study among larger sample is required. 
Table 1

\begin{tabular}{|c|c|c|c|c|}
\hline Impacted Third Molars & Male & Female & Total & Percentage \\
\hline Maxilla & 83 & 70 & 153 & $25.7 \%$ \\
\hline Mandible & 254 & 188 & 442 & $74.3 \%$ \\
\hline
\end{tabular}

Table 5

\begin{tabular}{|c|c|c|c|c|c|c|c|c|c|}
\hline \multirow{2}{*}{ Site } & \multirow{2}{*}{ Sex } & \multicolumn{2}{c|}{ Mesioangular } & \multicolumn{2}{c|}{ Distoangular } & \multicolumn{2}{c|}{ Vertical } & \multicolumn{2}{c|}{ Horizontal } \\
\cline { 3 - 9 } & & No. & $\boldsymbol{\%}$ & No. & \% & No. & \% & No. & \% \\
\hline \multirow{2}{*}{ Mandible } & Males & 178 & 70 & 20 & 7.8 & 45 & 17.7 & 11 & 4.3 \\
\cline { 2 - 10 } & Females & 140 & 74.4 & 18 & 9.5 & 22 & 11.7 & 8 & 4.2 \\
\hline \multirow{2}{*}{ Maxilla } & Males & 33 & 39.7 & 18 & 21.6 & 31 & 37.3 & 1 & 1.2 \\
\cline { 2 - 10 } & Females & 28 & 40 & 14 & 20 & 28 & 40 & 0 & 0 \\
\hline
\end{tabular}

\section{Conclusion}

The pattern of third molar impactions presented a higher percentage of impactions in females, with predominance in mandible and mesioangular being the commonest.

\section{Acknowledgement}

The authors would like to acknowledge \& Thank Zain ul Arifeen, Maryam Nisar, and Ayesha Nisar Wani \& Ayera Bashir for their help \& continuous support.

\section{References}

1. Lima CJ, Silva LC, Melo MR, Santos JA, Santos TS. Evaluation of the agreement by examiners according to classifications of third molars. Med Oral Patol Oral Cir Bucal 2012; 17:e281-e216

2. Ma'aita J, Alwrikat A. Is the mandibular third molar a risk factor for mandibular angle fracture? Oral Surg Oral Med Oral Pathol Oral Radiol Endod 2000;89:143-6.

3. Kaya GS, Aslan M, Ömezli MM, Dayi E. Some morphological features related to mandibular third molar impaction. J Clin Exp Dent 2010;2:e12-e7.

4. Hattab FN, Rawashdeh MA, Fahmy MS. Impaction status of third molars in Jordanian students. Oral Surg Oral Med Oral Pathol Radiol Endod 1995;79:24-9.

5. Scherstén E, Lysell L, Rohlin M. Prevalence of impacted third molars in dental students. Swed Dent J 1989;13:7-13.

6. Brown LH, Berkman S, Cohen D, Kaplan AL, Rosenberg M. A radiological study of the frequency and distribution of impacted teeth. J Dent Assoc S Afr 1982;37:627-30.

7. Fanning EA, Moorrees CF. A comparison of permanent mandibular molar formation in Australian aborigines and Caucasoids. Arch Oral Biol 1969;14:999-1006.

8. Haidar Z, Shalhoub SY. The incidence of impacted wisdom teeth in a Saudi community. Int J Oral Maxillofac Surg 1986;15:569-71.

9. Kramer RM, Williams AC. The incidence of impacted teeth. A survey at Harlem hospital. Oral Surg Oral Med Oral Pathol 1970;29:237-41.

10. Quek SL, Tay CK, Tay KH, Toh SL, Lim KC. Pattern of third molar impaction in a Singapore Chinese population: a retrospective radiographic survey. Int J Oral Maxillafac Surg 2003;32:548-52.

11. Hugoson A, Kugelberg CF. The prevalence of third molars in a Swedish population. An epidemiological study. Community Dent Health 1988;5:121-38.

12. Gann SM, Lewis AB, Bonne B:Third molar formation and its development course. Angle Ortho 1962;32:271-9.

13. Almendros-Marqués N, Alaejos-Algarra E, QuinterosBorgarello M, Berini-Aytés L, Gay-Escoda C. Factors influencing the prophylactic removal of asymptomatic impacted lower third molars. Int J Oral Maxillofac Surg 2008;37:29-35.

14. Breik O, Grubor D. The incidence of mandibular third molar impactions in different skeletal face types. Aust Dent $J$ 2008;53:320-4.

15. Bishara SE. Impacted maxillary canines:a review. Am J Orthod Dentofacial Orthop 1992;101:159-71.

16. Morris CR, Jerman AC. Panoramic radiographic survey: a study of embedded third molars. J Oral Surg 1971;29:122-5.

17. Montelius GA. Impacted teeth: A comparative study of Chinese and Caucasian dentitions. J Dent Res 1932;12:931-8.

18. Hassan AH. Pattern of third molar impaction in a Saudi population. Clin Cosmet Investig Dent 2010;2:109-13.

19. Hashemipour MA, Tahmasbi-Arashlow M, Fahimi-Hanzaei F. Incidence of impacted mandibular and maxillary third molars: A radiographic study in a Southeast Iran population. Med Oral Patol Oral Cir Bucal 2013;18:e140-5.

20. Kim JC, Choi SS, Wang SJ, Kim SG. Minor complications after mandibular third molar surgery: Type, incidence, and possible prevention. Oral Surg Oral Med Oral Pathol Oral Radiol Endod 2006;102:e4-11.

21. Obiechina AE, Arotiba JT, Fasola AO. Third molar impaction: Evaluation of the symptoms and pattern of impaction of mandibular third molar teeth in Nigerians. Odontostomatol Trop 2001;24:22-5.

How to cite this article: Kishore K, Lone PA, Janbaaz ZA, Mehnaz, Lone BA. Evaluation of incidence and pattern of third molar impactions in Jammu region: A cross sectional study. Indian J Anat Surg Head Neck Brain 2019;5(2):64-6. 